\title{
Assessment and simulation of water and nitrogen transfer under furrow irrigation \\ D. Crevoisier ${ }^{1}$, Z. Popova ${ }^{2}$, J.C. Mailhol' ${ }^{1}$ P. Ruelle
}

Under Press in AGWAT (doi:1016/j agwat2007.10.021)

\begin{abstract}
The objective of this study is to simulate water and nitrogen transfers under two furrow irrigation technologies (Every furrow irrigation-EFI and Alternative Furrow Irrigation-AFI) on Chromic Luvisol in Sofia region, Bulgaria. A bi-dimensional water and solutes transport modeling approach, HYDRUS-2D model (Simunek et al. 1999), is adopted in order to consider the technology of irrigation and fertilization. The model is calibrated in six steps using detailed data observed in two cropped lysimeters. The data consist of water and nitrogen $(\mathrm{N})$ profiles below ridge and furrow bed, precipitation, drainage and water $/ \mathrm{N}$ uptake by plant. Hydrological components of the soil are derived from laboratory: water retention data (step i) and adjusted to field conditions when EFI is approximated by one-dimensional (step ii). Then a two-dimensional water flow is adopted in model simulations for parameter calibration and verification, under EFI (step iii) and under AFI technology (step iv). This model calibration and validation is then used to calibrate the solute transport parameters, that is the aim of step $\mathrm{v}$ and step vi. EFI and particularly AFI technologies points out the necessary 2D model using for the $\mathrm{N}$ transfer simulation under specific fertilizer applications. Thus, this calibrated model allows predicting the impact of furrow irrigation practices and distribution uniformity on drainage and nitrogen leaching under the studied conditions.
\end{abstract}

\section{Key words:}

HYDRUS-2D model calibration and validation, lysimeter experiments, furrow irrigation, alternative furrow irrigation, water and solute transfer parameters, drainage and nitrogen leaching

\section{1-Introduction}

Furrow irrigation is used on almost $60 \%$ of irrigated surfaces in USA and Bulgaria. This ratio is below 10\% in some European countries (France and Slovakia for instance). However about $90 \%$ of irrigated areas in the world are under surface irrigation, mainly by furrow irrigation (Tiercelin and Vidal 2006), which is low energy and investment consuming. Nevertheless, it is still to day considered as little efficient (around 40\%) in most parts of world, more especially in countries where modern leveling techniques are not utilized (Burt et al. 1997). This is the case of the Maghreb countries where, for water savings, farmers are strongly encouraged by their government, with an important financial help, to adopt microirrigation. On the other hand, furrow irrigation can be quite efficient under favorable soil conditions with appropriate management and design (Clemmens and Dedrick 1994, Varlev et al. 1998a).

Environmental impacts of furrow irrigation were studied in different countries in the 90-ties (Artiola 1991, Popova and Petrova 1993, Fernandez et al. 1994, Lehrsch et al. 2000). Lysimeter experiments on traditional furrow (EFI) and environmentally oriented alternative furrow irrigation/fertilization (AFI) were carried out in Chelopechene maize field (Sofia) in the period 1996-2000. It appears that under certain conditions N-leaching could be reduced by $20-30 \%$ by separating water and fertilizer application (Benjamin et al. 1998, Popova et al.

\footnotetext{
${ }^{1}$ Cemagref ; UMR G-eau BP 5095, 34033 Montpellier, France e-mail :jean-claude.mailhol@cemagref .fr

${ }^{2}$ N.Poushkarov Institute of soil science 7, Shosse Bankya ,Str, Sofia 1080, Bulgaria, email:zornitsa@techno-link.com
} 
1998, Varlev et al. 1998b, Popova et al. 2000). Evaluation of environmental impacts of combined irrigation and fertilization practices requires accurate estimation of different water and nitrogen $(\mathrm{N})$ fluxes within the "soil-plant" system and at its boundaries. Due to the geometry of the infiltration domain, transfers are rather bi-dimensional (2D) in furrow irrigation at the scale of a cross-section. A modeling approach adapted to a $2 \mathrm{D}$ water and solute transfer is more appropriate to simulate water and nitrogen balance more especially in the case of specific fertilization practices (Mailhol et al. 2001). Numerical simulation using adapted codes such HYDRUS-2D have been performed yet in order to analyze nitrogen transfers through a cross-sectional furrow subject to different water depth in the furrow bed and water application depth (Abbasi et al. 2004, Mailhol et al. 2007). They reveal the important role played by water depths (and water application depths) on the risks of $\mathrm{N}$ leaching for specific fertilization practices consisting on $\mathrm{N}$ accumulation on the top of the ridge. High irrigation rates (resulting from both high water depths and opportunity times) tend to considerably reduce the difference between the two initial $\mathrm{N}$ profiles measured under ridge and under furrow respectively (Mailhol et al., 2007).

The objective of the study is to elaborate an operative methodology for HYDRUS-2D model (Simunek et al. 1999) calibration in order to use it for simulating water and nitrogen transfer under EFI and AFI practices through a cross-sectional furrow. We assume that water and nitrogen transfer process existing at a lysimeter scale can be simulated in a cross-sectional furrow by HYDRUS-2D for adequate flow depths and opportunity times. This study deals first with model calibration (step i and ii) and verification (iii and iv) of water transfers parameters, second with the use of these parameters to calibrate nitrogen transfers parameters ( $\mathrm{v}$ and vi). The model calibrated for EFI/AFI could be then used to estimate environmental risks resulting from furrow irrigation technology associated to fertilization practices.

\section{Materials and methods}

\section{2-1.Experimental approach}

Maize was cultivated under a free draining furrow irrigation system (furrow spacing $=$ $0.75 \mathrm{~m}$ ) with no limited fertilization in a 2 ha plot at Chelopechene (Sofia region). In this plot two lysimeters $\left(2 \mathrm{~m}\right.$ depth and $20 \mathrm{~m}^{2}$ ) were installed for the period 1996-1998. A variety Kneja 509 was sown on 14/05/1997 with a plant density $5.6 \mathrm{pl} / \mathrm{m} 2$. The soil is Chromic Luvisol and its texture is presented in Table 1. Soil water storage at field capacity is of $125 \mathrm{~mm} / \mathrm{m}$ and saturation conductivity Ks of the layers below the plough layer (from 33 to $130 \mathrm{~cm}$ ) ranges from 15 to $60 \mathrm{~cm}^{-d a y}{ }^{-1}$.

A statistical study preformed over a thirty-year period states that irrigation season (July-August) in 1997 was moderately wet (probability of precipitation excess $\mathrm{PI}=26 \%$ ).

Two technologies of water and fertilizer applications were used in both lysimeters. The first technology was traditional and referred to as EFI. Irrigation and fertilization, except for pre-sowing fertilization rate, were applied in each furrow. The second one was AFI since water was applied in every other furrow. The fertilization practice consisted on ammonium nitrate fertilizer uniformly applied before sowing while the remaining part was spread in the dry furrows only. The rates and timing of irrigation and fertilization were equivalent for EFI and AFI technologies.

The fertilization practice consisted of uniform distribution of the bigger part of ammonium nitrate fertilizer (200 kg N.ha-1) on the soil surface before sowing (on 24/04, day 114 ) and fertilizer band placement (50 kg N.ha-1) on 05/08 (day 217), the fertilizer was spread along the rows for EFI and the "dry" furrows only for AFI technology.

Observed data (Popova et al. 1998, Varlev et al. 1998b) and analytical results (Popova et al. 2001, Popova and Shopova 2002) were used for HYDRUS2D model calibration. 
Tensiometers were installed to monitor soil water pressure head $(\mathrm{PH})$ under dry and wet furrow beds and ridges at 40, 70, 100 and $130 \mathrm{~cm}$ depth on 17/07/1997 (Fig.1). Soil water content (SW) was also observed under furrow beds and ridges at eight different depths (10, $20,30,40,50,60,80$ and $100 \mathrm{~cm}$ ) by gravimetric method each decade, the soil surface being taken as the reference level. Opportunity times and flow depths were measured for instrumented furrows. First irrigation was small $(13 \mathrm{~mm})$ and applied a month after sowing on $13 / 06$ (day 164). The second and third irrigation depths were equal $(60 \mathrm{~mm})$ and thus presented the main irrigation water supply. They were delivered on 17/07 (day 198) and 12/08 (day 224) respectively at pre-irrigation soil moisture $75 \%$ and $85 \%$ of field capacity (FC) when irrigation requirements were respectively $86 \mathrm{~mm}$ and $50 \mathrm{~mm}$.

Water balance terms, as precipitation (P), irrigation (Ir) and drainage below the bottom boundary (Dr), were measured volumetrically all over the experimental year. Dr was measured once a week during the vegetation period. Water balance was performed over ten days in order to derive observed crop evapotranspiration (ETcrop) for CERES evaluation (Popova et al. 2001).

$\mathrm{N}$-content in the soil layers $0-30,30-60$ and $60-90 \mathrm{~cm}$ was observed in the profiles under dry/wet furrow beds and ridges eight times during the season (day: 126, 156, 171, 202, $218,226,231,335)$ to evaluate the evolution of mineral $\mathrm{N}$-storage in the soil. For the soil $\mathrm{N}$ concentration evaluation, five soil samples were collected and mixed for a given depth. Nitrogen balance measurements included also N-leaching (N1) at the bottom of the lysimeter and N-uptake (Ncrop) by plants (Popova et al. 1999b). The latter two terms were evaluated by analyzing the concentration of $\mathrm{N}$ in the drainage and the crop organs over the season. Soil and drainage water were analyzed for N-NO3 and N-NH4 following the procedure outlined by the Application Note List-ASN 65-31/84 and 65-32/84 of Techator Company. Mineral N was extracted by $2 \mathrm{M}$ KCL.

\section{2-2.Modeling approach}

Assumption and strategy

Modeling is used for simulating the water and nitrogen transport process during the vegetation period through a cross-sectional furrow within a lysimeter. Due to the domain geometry and the specificity of the fertilization practice (Mailhol et al., 2001), the 2D water and solute transport model HYDRUS-2D is chosen, this latter is one of the most used in water and solute transfers modeling and benefits of numerous validation case studies published recently (Gärdenäs et al. 2006, Ajdary et al. 2007, Ndiaye et al. 2007).

The governing flow equation is given by the Richards' equation with a sink term (S) representing the volume of water removed per unit time from a unit volume of soil due to plant water uptake. S is defined according to the (Feddes et al. 1974) water stress reduction model associated to the root density model proposed by (van Genuchten 1987). The required parameters used are the ones suggested by (Wesseling 1991). The resulting root extraction model enables the simulation of actual transpiration, the specific parameters of the Feddes model for corn being drawn from the crop list proposed by HYDRUS. Initial and boundary conditions prevailing in furrow irrigation are presented in Mailhol et al., (2001), with the calculation grid adapted to the geometry of the domain.

The pertinence of a model based on the Richards equations on a soil having high clay content is questionable due to the cracking phenomenon that generally occurs on this soil type furrow irrigated (Mailhol and Gonzalez 1993). Although precipitation frequency mitigates the importance of soil cracking which appeared moderate, we cannot certificate that preferential 
flows do not exist. Nevertheless, we assume that the soil conditions do not invalidate the HYDRUS-2D application.

HYDRUS-2D solves numerically the convection-diffusion equation with zero- and first-order reaction and sink term. It predicts the fate of a component in soil under gaseous, liquid and solid state. In this study, $\mathrm{NO}^{--}$transfer only is simulated and the following equation is solved.

$$
\frac{\partial \theta c_{N O 3}}{\partial t}=\frac{\partial}{\partial x_{i}}\left(\theta D_{i j} \frac{\partial C_{N O 3}}{\partial x_{j}}\right)-\frac{\partial q_{i} C_{N O}}{\partial x_{i}}+\mu_{w} \theta-S C_{N O 3 s}
$$

, where $\mathrm{c}_{\mathrm{NO} 3}$ is the nitrate concentration in soil $\left[\mathrm{ML}^{-3}\right], \mathrm{q}_{\mathrm{i}}$ is the $\mathrm{i}$-th component of the volumetric flux $\left[\mathrm{LT}^{-1}\right], \mathrm{D}_{\mathrm{ij}}$ is the dispersion coefficient tensor $\left[\mathrm{L}^{2} \mathrm{~T}^{-1}\right], \mu_{\mathrm{w}}$ is zero-order rate constants for nitrate in the soil solution $\left[\mathrm{ML}^{-3} \mathrm{~T}^{-1}\right], \mathrm{S}$ is the sink term of the water flow in the Richards equation, $\mathrm{c}_{\mathrm{NO} 3 \mathrm{~s}}$ is the concentration of the sink term $\left[\mathrm{ML}^{-3}\right]$.

Volatilization and gaseous state of nitrate is neglected. Its concentration depends on oxygen content, $\mathrm{pH}$ and temperature (Wendland 1994); conditions in which experiments have been performed strengthen this assumption. Soil tillage and application of fertilizer by ammonium nitrate granules reduce also this concentration (Stanford and Epstein 1974, Olesen et al. 1997). Adsorption of nitrate by soil matrix is also neglected with regards to other processes (Huygens et al. 2007). Main nitrate reactive processes are nitrate production resulting from ammonium degradation. These processes are all gathered in the zero-order reaction controlled by $\mu_{\mathrm{w}}$ coefficient. This zero-order constant is calibrated for severals soil regions for each model run. These regions were defined on the basis of homogeneity criteria in terms of temperature, ammonium, water and oxygen content during each model run. This assumption and this calibration method are both disputable. But, a more complex method would be awkward to perform. Indeed, the chemical, biochemical and physical processes occurring during the cropping season are very difficult to model. This difficulty also results from a lack of data and because Chromic Luvisol has a particular tendency to produce ammonium (Boneva 1970).

\section{Model calibration}

Model calibration consists in a six steps procedure. In the first step, laboratory water retention curve (Koleva 1973) were regressed with the van Genuchten water retention curve (van Genuchten 1980). Obtained van Genuchten parameters were then adjusted to field conditions by comparison of simulated SW/PH and drainage Dr with the observations in EFI lysimeter when a 1D water transfer (step ii) is adopted (Table 2 and Fig.2). From this step, atmospheric conditions (e.g. soil evaporation: Esoil and potential transpiration: Tp) are simulated by CERES-maize model (Popova et al. 2001). Bottom boundary condition is free drainage that is consistent with the lysimeter characteristics.

Simulating water transfer by a 1D model in the furrow case seems a little relevant and in disagreement with our previous purposes. But, for the EFI case, it would seem that according to the pressure evolution (Fig.1) soil water content becomes homogenous within the soil profile. This homogeneous phenomenon depends on the water amount delivered during irrigation (or by rainfall) but it is also ruled by root extraction. That could justify the utilization of a 1D model to estimate a water balance from $\mathrm{z}=0$ to $\mathrm{z}=1 \mathrm{~m}$ depth and to perform conveniently a first calibration of the soil hydraulic parameters. Obviously, the justification of a 1D approach is more acceptable during a redistribution process than during an infiltration process. The convenient character of a 1D simulation resides in the fact that it allows a simulation in a single model run at the opposite of a $2 \mathrm{D}$ model which requires to update the initial water profile after each irrigation event for simulating redistribution, and vis et versa. 
A quasi semi-circular furrow shape of $15 \mathrm{~cm}$ depth is adopted to mimic the infiltration conditions prevailing on the plot. Boundary conditions for simulating EFI and AFI are given in Fig.3. Fig. 3a and Fig.3e presents the boundary conditions for step (iii) and for step (iv) respectively. Fig. $3 \mathrm{~b}$ and Fig.3f give a graphical representation of the $2 \mathrm{~m}$ soil column.. The latter consists of four soil layers: a 30-cm A-horizon, a B-horizon composed of 2 similar soil layers $(30-75 \mathrm{~cm}$ and $75-120 \mathrm{~cm})$ and a C-horizon which extends as a homogenous soil layer 4 to $200 \mathrm{~cm}$. Initial soil water content is taken from SW observations on 26/05/1997. Finite element mesh of numerical simulations is designed to be denser near the top boundary to avoid numerical divergence where moisture gradients are the highest. Eight observation nodes of SW are defined between the furrow and the row at the depths corresponding to soil sampling (Fig.3-c). Eight observation nodes for $\mathrm{PH}$ are defined under furrow bed and row at the depths corresponding to tensiometer position in EFI lysimeter (Fig.3d). Ten observation nodes (Fig.3g) of PH are defined at the depths of tensiometers position for the dry/wet furrow and the ridge in AFI lysimeter for the simulations in step (iv). Note that a zero flux plan is assumed at the vertical boundaries.

In step (iii) and in step (iv) the 2D water flow is adopted with the adjusted parameters of the retention curve. Irrigation events are simulated as they were really applied in terms of opportunity time, wetted perimeter (presented in blue in Fig.3a for EFI and in Fig.3e for AFI). Simulations were made in eight model runs (soil profile at the end of run (i) constituting the initial soil conditions of run $(i+1)$ ) because each irrigation event has its proper parameters (opportunity time, water depths) and root progression has to be updated. The eight model runs were performed from sowing (14/05, day 126) to the first irrigation event (13/06, day 164), for the irrigation itself, from the end of the first irrigation to a soil sampling date (20/06, day 171), from day 171 to the second irrigation on 17/07 (day 198), for the second and third irrigation events on 17/07 (day 198) and 12/08 (day 224) and the period between them and from the third irrigation to harvest (25/09, day 268). SW profile observed at sowing is used as starting for the first period. Simulated SW profile at the end of each period is introduced as initial for the next one. Opportunity times of $23 \mathrm{~min}$ for the first, $1 \mathrm{~h} 07 \mathrm{~min}$ for the second and $2 \mathrm{~h}$ for the third irrigation and wetted perimeter values are applied in the EFI simulation. Opportunity times of $49 \mathrm{~min}, 3 \mathrm{~h} 20 \mathrm{~min}$ and $4 \mathrm{~h} 15 \mathrm{~min}$ are respectively used for the first, second and third irrigation in the AFI simulation.

Independent observations of the dynamic of PH (cm) in EFI and AFI lysimeters are used to validate both step (iii) and step (iv). Calculations were carried out in four consecutive periods starting with the second irrigation on 17/07 (day 198), the period between second and third irrigation, the third irrigation on 12/08 (day 224) and the next period till harvest (day 268). As previously explained, observed PH profile before second irrigation is used as starting. Computed PH profile at the end of each period was introduced as initial PH profile for the next one. Tensiometers observations in every other day allowed checking the simulated evolution of PH within the root zone (at 40, 70 and $100 \mathrm{~cm}$ depth) and below it (at $130 \mathrm{~cm}$ depth). Readings out of range of reliable tensiometer functioning (for instance $\mathrm{PH}=$ $420 \mathrm{~cm}$ at $40 \mathrm{~cm}$ depth and $\mathrm{PH}=-650 \mathrm{~cm}$ respectively at 70 and $100 \mathrm{~cm}$ depth), observed in periods of no water supply and intensive crop water uptake, are excluded from analyses.

The two last operative methodologies step (v) and step (vi) are devoted to the calibration of the nitrogen transfer parameters using observed data from lysimeters trials under EFI/AFI. The effort of calibration is focused on the two parameters of Eq. 1:

- The zero-order rate constant for nitrate solute creation in the liquid $\mu_{\mathrm{w}}\left(\mathrm{mg}_{\mathrm{NO} 3} / \mathrm{cm}^{3} / \mathrm{h}\right)$. The coefficient of nitrate production by ammonium degradation in the soil depends on soil properties (water/ammonium content, air presence, biochemical activity) and usually ranges between 0.01 h-1 and 0.001 h-1 (Cho 1971, Misra et al. 1974, Vereecken et al. 1991). The coefficient $\mu_{\mathrm{w}}$ is calibrated for several periods and soil regions under EFI and AFI. Presuming 
different soil properties, air presence and ammonium concentrations influence upon the amount of nitrate creation, $\mathrm{m}_{\mathrm{w}}$ coefficient is validated for five (EFI) or six (AFI) soil regions and five time periods. In order to better account for the lateral heterogeneity of ammonium and water, the soil depth from 0 to $30 \mathrm{~cm}$ (A-horizon) is divided into two (for EFI) or three (for AFI) vertical regions Fig.3b and Fig.3f): one under the wet furrow where ammonium degradation in nitrate is comparatively low, another two of accelerated nitrate production under the ridge and the dry furrow. The remaining soil part is divided in two regions: below (30-120 cm: B-horizon) and a last homogenous region (horizon-c) extending from 120 to $200 \mathrm{~cm}$.

- Maximum concentration of nitrate in the sink term $\mathrm{c}_{\mathrm{NO} 3 \mathrm{~S}}\left(\mathrm{mg}_{\mathrm{NO} 3} / \mathrm{cm} 3\right)$. Nitrate uptake from the simulation domain depends on plant water uptake, concentration of the soil solution and maximal nitrate concentration that can be extracted by plant. In order to validate the concentration $\mathrm{c}_{\mathrm{NO} 3 \mathrm{~S}}$ of the sink term, the observed values of plant $\mathrm{N}$-uptake are used (Popova et al. 1999a).

Proper initial conditions are necessary for numerical simulations in the furrow/ridge cross section. However HYDRUS-2D cannot simulate dissolution of solid fertilizer. Thus calibrations steps (v) and (vi) are initialized 42 days after the application of the big rate of $200 \mathrm{~kg} \mathrm{~N} / \mathrm{ha}$, i.e. on day 156 (5/06/1997), when the fertilizer in the field is completely dissolved by precipitation. Initial soil water (SW) in the simulated domain is taken from the output of previous simulations (steps iii and iv) while initial soil nitrate $\left(\mathrm{c}_{\mathrm{NO} 3}\right)$ is based on observed concentrations. It should be noted that there is no observations available in $\mathrm{C}$ horizon (120-200) where $\mathrm{N}$ content is assumed to be 0 at the beginning of simulations.

\section{3-Results and discussion}

The experimental results are accurately discussed in Popova et al., (1998, 1999a, 1999b, 2002). We only focus here on modelling results.

Step (ii) served to validate the calibrated values of the hydrodynamic model parameters by comparing numerical results against those observed in EFI lysimeter. Acceptable agreement between measured and simulated SW was obtained when parameter $\mathrm{n}$ (derived from laboratory data) was modified from $n=1.33$ to $n=1.44$ for A-horizon (Fig.4a and $4 b$ ) and from $n=1.17$ to $n=1.32$ for B-horizons (Fig.4c and 4d). Saturated water content $\theta_{\mathrm{s}}$ of the Bhorizon was reduced from 0.44 to 0.34 (Table 2). Root mean square error (RMSE) are 0.061 $\mathrm{cm}^{3} . \mathrm{cm}^{-3}, 0.024 \mathrm{~cm}^{3} \cdot \mathrm{cm}^{-3}, 0.031 \mathrm{~cm}^{3} \cdot \mathrm{cm}^{-3}$ and $0.033 \mathrm{~cm}^{3} \cdot \mathrm{cm}^{-3}$ respectively, the worst error is obtained for the surface layer where soil variability and flux variations are difficult to represent. It should be noted that adjusted VG curve for layer 2 gave lower $\theta$ estimates (about $0.10 \mathrm{~m}^{3} \mathrm{~m}^{-3}$ less, Fig.2b) when compared to laboratory $\theta$ for the same $\mathrm{PH}$ value. However, soil reservoir capacity, which depends on the slope of the water retention curve, is kept the same in the model tuning. Adjusted $\mathrm{vG}$ parameters give acceptable simulations of the volumetric water contents for all the soil layers and consequently total available water in the root zone (Fig4e) is well enough simulated (RMSE $13.1 \mathrm{~mm}$ ). The impacts of irrigation and rainy events (Fig.4f) are clearly visible on these simulations.

Step (iii) is similar to step (ii) but in 2D transfer process. As the simulations do not highlight significant differences regarding the soil water content distribution, the graphical presentations are not necessary. But, step (iii) and (iv) are fundamental because a 2D N transfer simulation needs a well knowledge of the a 2D water fluxes.

Graphical test of SW in the wet and dry furrow is acceptable. Cumulative drainage predictions are compared with field observations in Fig.5. Seasonal drainage under AFI, although weak, is two time higher that under EFI, this behaviour being respected by the model. 
AFI required treble application time for the same application depth $(60 \mathrm{~mm})$. Drainage is smoothed in simulations while observed evolution is stepwise especially following the second irrigation on day 198 where probably some cracks have induced preferential flow paths. Nevertheless one can consider that simulated total seasonal drainage is close enough to observed one.

A graphical test validation of the $2 \mathrm{D}$ modeling approach shows that simulated $\mathrm{PH}$ is close to the tensiometer observations both for furrow bed and furrow ridge in EFI lysimeter. $\mathrm{Ce}$, the coefficient of efficiency according to Nash-Sutcliffe (1970) is within the range 0.490.96 for the period of soil drying between day 230 and day 268 and it is lower but acceptable (from 0.41 to 0.63 ) for data observed during the whole irrigation season, with multiple wetting and soil drying.

Graphical results of step (iv) presented in Fg.6 validate model predictions of PH below the irrigated/non-irrigated furrows and the furrow ridge against independent tensiometers observations in the case of AFI. The comparisons between simulated and observed PH evolutions at 40, 70, 100 depths are acceptable with $\mathrm{Ce}$ in the same range than EFI simulations. Simulated PH follows the trend of tensiometers readings in dry/wet furrow and ridge during the irrigation season. However, a slight overestimation of simulated $\mathrm{PH}$ in the soil profile below dry furrow bed and furrow ridge can be observed.

Calibrated values of solute transfer $\mu_{\mathrm{w}}$ parameter and concentration of sink term $\mathrm{c}_{\mathrm{NO} 3 \mathrm{~s}}$ during step (v) and (vi) are given in Table 3. The graphical comparison between observed and simulated profiles of soil nitrate concentrations relative to EFI lysimeter and the period 5/06 (day 156)-25/09 (day 268) is shown in Fig.7. Although $200 \mathrm{~kg} \mathrm{~N} / \mathrm{ha}$ solid fertilizer is uniformly distributed on 24/04 (day 114), significant part of it remains still on the top of the ridge at the start of simulations (5/06, day 156). Fig.7 shows that simulated profiles follow the trend of observed nitrate concentration 15, 46, 70 and 112 days after the beginning of the numerical solution. The numerical results are correct, in spit of some small gaps between simulated and observed values under the furrow and two days after the third irrigation event (14/08, day 226). These results indicate that parameters from Table 3 produce appropriate simulations of soil nitrate and N-uptake in case of EFI.

Numerical results relative to nitrogen transfers under EFI are better than those simulated for AFI. The combined effects of soil acidity and alternate-furrow irrigation may be the reason of slower nitrification rate and significant denitrification in the field. Obviously the simplified Eq.(1) cannot take these factors of nitrogen transfer under AFI into account. However, the fit between simulated and observed residual nitrate profiles (on 25/09/1997, day 268 ) is quite satisfactory under alternate-furrow irrigation (Fig.8).

Nitrate advancing in the simulation domain immediately after second (17/07, day 198) and third (12/08, day 224) irrigation events are shown in Fig.9 for both irrigation technologies respectively. Transfer of $\mathrm{NO}_{3}$ is comparatively uniform across the domain of EFI numerical simulation (Fig.9a and 9b) when nitrate concentrations are high under dry furrow and ridge (Fig.9c) after second irrigation in AFI simulations. Nitrate concentrations remain still high in the clay layer below "dry furrow" even after the third irrigation event (Fig.9d).

Cumulative $\mathrm{N}$-uptake is correctly computed under both irrigation practices when the calibrated maximum concentrations of the sink term $\mathrm{c}_{\mathrm{NO} 3 \mathrm{~s}}$ are used. The fit between simulated and observed N-uptake is satisfactory as illustrated in Fig.10

Computed and observed N-leaching at the bottom of the lysimeter is also compared (Fig.11). The figure indicates that the migration of nitrate towards the bottom boundary $(2 \mathrm{~m}$ depth) is smoother and slower in model simulations than in lysimeters' observations. Numerical results however confirm the findings of the lysimeters trials that seasonal $\mathrm{N}$ leaching in absolute terms is:

1) comparatively small (1-3\% of applied $\mathrm{N})$ under both irrigation practices; 
2) it is double in the case of AFI.

\section{Conclusion}

A six-step operative calibration procedure of HYDRUS2D model (Simunek et al.1999) was elaborated for simulating a bi-dimensional water transfer under EF/AF irrigation practices. In the first 4 steps, variables observed in cropped lysimeters (precipitation, drainage-Dr, soil water-SW and pressure head-PH in the soil regions below irrigated/nonirrigated furrow and furrow ridge) as well as simulated water uptake by plant roots and soil surface evaporation (CERES-maize 1D model) were used to verify the mathematical accuracy of HYDRUS2D predictions.

Graphical and model performance criterions attest of better simulations when a 2D water transfer model is used instead of a 1D more especially in case of AFI. The results of experiments and model simulations indicate that water is transported through the whole soil monolith under EFI and under the wet furrow only for AFI. Drainage below $2 \mathrm{~m}$ is small (20$40 \mathrm{~mm} /$ season) under EFI/AFI technologies. However it is double in the case of AFI due to a highest opportunity time.

In the two last steps, comparison between simulated and observed $\mathrm{NO}_{3}$-content profiles under the furrow bed and the ridge, $\mathrm{N}$-uptake by the plant and $\mathrm{N}$-leach below $2 \mathrm{~m}$ depth show that:

- Soil nitrate simulations are acceptably precise in the case of EFI.

- The simulation of soil nitrates in the case AFI are less precise in the period between the second and the third irrigation, when important water fluxes occur. However the residual nitrate in the soil is satisfactory accurate at the end of the simulation period on 25/09/1997.

- Downward nitrogen transfer in the case study signifies that seasonal N-

leaching below $2 \mathrm{~m}$ depth is comparatively small under EF/AF irrigation (1-3\% of applied N). However leaching which follows the same tendency as drainage, is higher (up to double) in the case of AFI.

The originality of this work resides in the fact that the AFI technology that was experimented several times by researchers was never modeled before. Consequently, the applicability of a numerical code such HYDRUS and its implementation could be considered as an interesting challenge. The present work should encourage future researches for adapting the methodology to their environmental conditions. Preliminarily, an experimental protocol should be implemented for model validation. Thus, HYDRUS-2D model could be used in a predictive mode to simulate the fate of nitrogen relative to $\mathrm{EF} / \mathrm{AF}$ irrigation practices to help identify agricultural practices that mitigate the environmental risks.

Acknowledgements: We gratefully acknowledge the contribution of Prof. Varlev, Prof. Ikonomova and Dr. Kutev to initiate an interdisciplinary experimental study of joint fertilization and irrigation practices in EFI and AFI lysimeters in Chelopechene site almost 10 years ago. The discussions and common work performed in the 90-ies was very important to get insight the problem and latter apply the model. ECONET 2004 program of French Foreign Office sponsored partially the research by financing the exchange of the international team for preparing this paper.

We also gratefully acknowledge an anonymous reviewer for his constructive advices.

\section{References}


Abbasi, F., J. Feyen, and M. T. van Genuchten. 2004. Two-dimensional simulation of water flow and solute transport below furrows: model calibration and validation. Journal of Hydrology 290:63-79.

Ajdary, K., D. K. Singh, A. K. Singh, and M. Khanna. 2007. Modelling of nitrogen leaching from experimental onion field under drip fertigation. Agricultural Water Management 89:15-28.

Artiola, J. F. 1991. Nonuniform leaching of nitrate and other solutes in a furrow-irrigated, sludge amended field. Commun.Soil Sci.Plant Anal. 22:1013-1030.

Benjamin, J. G., L. K. Porter, H. R. Duke, L. R. Ahuja, and G. Butters. 1998. Nitrogen movement with furrow irrigation method and fertiliser band placement. Soil Sci. Soc. Am. J. 62:1103-1108.

Boneva, K. 1970. Effect of the main soil types in the Kazanluk valley on the growth and productivity of Kazanluk oil-bearing rose (in Bulgarian with summery in English). Soil science and agrochemistry 5:3-10.

Burt, C. M., A. J. Clemmens, T. S. Strelkoff, K. H. Solomon, R. D. Bliesner, L. A. Hardy, T. A. Howell, and D. E. Eisenhauer. 1997. Irrigation performance measures : Efficiency and uniformity. Journal of irrigation and drainage engineering 123:423-442.

Cho, C. M. 1971. Convective transport of ammonium with nitrification in soil. Can J Fish Aquat Sci 51:339-350.

Clemmens, A., and J. A. R. Dedrick. 1994. Irrigation techniques and evaluations. Pages 64.103 in K. K. T. a. B. Yaron, editor. Management of Water Use in Agriculture. Springer Verlag, Berlin.

Feddes, R. A., E. Bresler, and S. P. Neuman. 1974. Field test of a modified numerical model for water uptake by root systems. Water resources reasearch 10:1199-1206.

Fernandez, J. E., F. Moreno, J. M. Cabrera, and E. F.-B. Murillo. 1994. Water and nitrogen use efficiency in a maize crop in southern Spain. in Confer. on land and water resource management in the mediterranean region, Inst. Mediter. Bari, Italy.

Gärdenäs, A. I., J. Simunek, N. Jarvis, and M. T. van Genuchten. 2006. Two-dimensional modelling of preferential water flow and pesticide transport from a tile-drained field. Journal of Hydrology 329:647-660.

Huygens, D., T. Rütting, P. Boeckx, O. van Cleemput, R. Godoy, and C. Müller. 2007. Soil nitrogen conservation mechanisms in a pristine south Chilean Nothofagus forest ecosystem. Soil Biology and Biochemistry 39:2448-2458.

Koleva, S. 1973. Water retention curves at different soil density level ( in Bulgarian). Soil science and agrochemistry 4.

Lehrsch, G. A., R. E. Sojka, and D. T. Westermann. 2000. Nitrogen placement, row, spacing, and furrow irrigation water positioning effects on corn yield. Agronomy Journal 92:1266-1275.

Mailhol, J.-C., D. Crevoisier, and K. Triki. 2007. Impact of water application conditions on nitrogen leaching under furrow irrigation: Experimental and modelling approaches. Agricultural Water Management 87:275-284.

Mailhol, J. C., and G. Gonzalez. 1993. Furrow irrigation model for real-time applications on cracking soils. Journal of Irrig. Drain. Engin. ASCE 119:768-783.

Mailhol, J.-C., P. Ruelle, and I. Nemeth. 2001. Impact of fertilisation practices on nitrogen leaching under irrigation. Irrigation science 20:139-147.

Nash, J. E., and J. V. Sutcliffe. 1970. River flow forecasting through conceptual models part I - A discussion of principles. Journal of Hydrology 10:282-290.

Misra, C., D. R. Nielsen, and J. W. Biggar. 1974. Nitrogen transformations in a soil during leaching; III. Nitrate reduction in soil columns. Soil sci. soc. Am. Proc. 38:300-304. 
Ndiaye, B., J. Molénat, V. Hallaire, C. Gascuel, and Y. Hamon. 2007. Effects of agricultural practices on hydraulic properties and water movement in soils in Brittany (France). Soil and Tillage Research 93:251-263.

Olesen, T., B. B. Griffiths, K. Henriksen, P. Moldrup, and R. Wheatley. 1997. Modeling diffusion and reaction in soils : V. nitrogen transformations in organic manureamended soil. Soil science 162:157-168.

Popova, Z., B. Gabrielle, B. Leviel, and M. Kercheva. 2001. Test of biological module of CERES-maize model in lysimeters on Chromic Luvisol. Soil science and agrochemistry XXXVI:4-6.

Popova, Z., E. Ikonomova, I. Varlev, and V. Kutev. 1998. Alternative Furrow Irrigation under the conditions of cinnamonic forest red soils (part two): deep percolation and environmental impact. Pages 470-477 in Proceedings of the Research Institute for Irrigation, Drainage and Hydraulic Engineering (in Bulgarian).

Popova, Z., B. Leviel, M. Kercheva, I. Varlev, and G. Gosse. 1999a. Linking water in Ndynamics of cropped soil into risk of ground water pollution. Pages 41-42 in A. Musy, L. S. Pereira, and M. Fritsch, editors. Proceedings of 2nd Inter-Regional Conference of ICID on Environment-Water "Emerging Technologies for Sustainable Land Use and Water Management", Lausanne.

Popova, Z., and I. Petrova. 1993. Impact of Modeling in Furrow Irrigation Erosion. Pages 347-355 in Visherec, editor. proceedings of the international symposium "Farm lands erosion in temperate plains, environment and hills". Elsevier Science Publishers, Saint-Cloud, Paris.

Popova, Z., and D. Shopova. 2002. Water balance under maize in lysimeters on Chromic Luvisol. Soil science and agrochemistry XXXVII:5-10.

Popova, Z., D. Shopova, and L. Stanislavova. 1999b. Fertilization of maize and risk to environment under Chromic Luvisol conditions. Pages 918-920 in J. Bech, editor. Extended abstracts of 6th Int. Meeting "Soils with Mediterranean type of climate", Barcelona.

Popova, Z., I. Varlev, V. Kutev, and D. Shopova. 2000. Lysimeter study on ground water degradation due to different fertilisation and irrigation management. Soil science and agrochemistry 35:19-23.

Simunek, J., M. Sejna, and M. T. Van Genuchten. 1999. The HYDRUS-1D and HYDRUS2D codes for estimating unsaturated soil hydraulic and solutes transport parameters. in Agron Abstr 357.

Stanford, G., and E. Epstein. 1974. Nitrogen mineralisation - water relation in soils. Soil sci. soc. Am. Proc. 38:103-107.

Tiercelin, J. R., and A. Vidal. 2006. Traité d'irrigation (2nd edition), Lavoisier edition.

van Genuchten, M. T. 1980. A closed form equation for predicting the hydraulic conductivity of unsaturated soils. Soil Sci. Soc. Am. J. 44:892-898.

van Genuchten, M. T. 1987. A numerical model for water and solute movement in and below the root zone. Research report No 121. U.S. Salinity Laboratory, USDA, ARS, Riverside, California.

Varlev, I., Z. Popova, and I. Gospodinov. 1998a. Furrow surge irrigation as water saving technique. Pages 131-140 in L. S. Pereira and J. Gowing, editors. Selected papers of the first inter-Regional Conference of ICID "Environment - Water: Innovative Issues in Irrigation and Drainage", Lisbon.

Varlev, I., Z. Popova, and B. Mladenova. 1998b. Alternative Furrow Irrigation under the conditions of cinnamonic forest red soils (part one): uniformity of water distribution and yield. Pages 142-148 in Proceedings of the Research Institute for Irrigation, Drainage and Hydraulic Engineering (in Bulgarian). 
Vereecken, H., M. Vanclooster, M. Swerts, and J. Diels. 1991. Simulating water and nitrogen behavior in soil cropped with wheat. Fert. Res. 27:233-243.

Wendland, F. 1994. Modelling nitrate flow in the ground-water provinces of the "old" federal states of the federal republic of germany. Ecological modelling 75:385-397.

Wesseling, J. G. 1991. Meerjarige simulaties van grondwateronttrekking voo verschillende boden profielen, grondtrappen en gewassen met het model SWATRE (in Dutch). Report 152. Winand staring Centre, Wageningen. 


\begin{tabular}{|c|c|c|c|c|c|}
\hline \multirow[t]{2}{*}{ Depth, cm } & \multirow{2}{*}{$\begin{array}{l}\text { Soil texture } \\
\text { Classification }\end{array}$} & \multicolumn{3}{|c|}{ Soil particles, $\%$} & \multirow[t]{2}{*}{$\mathrm{Ks}(\mathrm{Lab}), \mathrm{cm} \mathrm{day}^{-1}$} \\
\hline & & $\begin{array}{l}\text { Clay } \\
<0,002 \mathrm{~mm}\end{array}$ & \begin{tabular}{|l} 
Silt \\
$0,002-0,05 \mathrm{~mm}$
\end{tabular} & \begin{tabular}{|l|} 
Sand \\
$0,05-2,00 \mathrm{~mm}$
\end{tabular} & \\
\hline $0-28$ & clay loam & 32 & 32 & 36 & 93,30 \\
\hline $33-45$ & clay & 43 & 27 & 30 & 15,90 \\
\hline $61-71$ & clay & 42 & 25 & 33 & 20,20 \\
\hline $95-130$ & Sandy clay loam & 24 & 15 & 61 & 39.90 \\
\hline
\end{tabular}

Table 1. Soil texture and laboratory based saturated hydraulic conductivity $(\mathrm{Ks}(\mathrm{Lab}))$, Chelopechene field.

\begin{tabular}{|l|l|llllll|}
\hline Layer-source & $\begin{array}{l}\text { Depth, } \\
\mathrm{cm}\end{array}$ & $\begin{array}{l}\mathrm{BD} \\
\mathrm{g} . \mathrm{cm}^{-3}\end{array}$ & $n$ & $\begin{array}{l}\alpha, \\
\mathrm{cm}^{-1}\end{array}$ & $\begin{array}{l}\theta_{r}, \\
\mathrm{~m}^{3} . \mathrm{m}^{-3}\end{array}$ & $\begin{array}{l}\theta_{s}, \\
\mathrm{~m}^{3} . \mathrm{m}^{-3}\end{array}$ & $\begin{array}{l}K_{s}, \\
\mathrm{~cm}^{-1} \text { day }\end{array}$ \\
\hline 1-labo & $0-28$ & 1.3 & 1.33 & 0.04 & 0.10 & 0.48 & 93,30 \\
1-pedotransfer & $0-28$ & & 1.44 & 0.012 & 0.08 & 0.45 & 17,08 \\
1-adjusted & $0-30$ & & 1.41 & 0.02 & 0.10 & 0.44 & 93,00 \\
\hline 2-labo & $33-45$ & 1.47 & 1.17 & 0.02 & 0.113 & 0.44 & 15,90 \\
2-pedotransfer & $33-45$ & & 1.32 & 0.016 & 0.09 & 0.43 & 8,49 \\
2-adjusted & $30-75$ & & 1.32 & 0.016 & 0.11 & 0.34 & 15,00 \\
\hline 3-labo & $33-45$ & 1.47 & 1.17 & 0.02 & 0.113 & 0.44 & 20,20 \\
3-pedotransfer & $61-71$ & & 1.32 & 0.016 & 0.09 & 0.44 & 8,97 \\
3-adjusted & $75-120$ & & 1.32 & 0.018 & 0.11 & 0.38 & 15,00 \\
\hline 4-labo & $90-100$ & 1.54 & 1.34 & 0.004 & 0.06 & 0.39 & 39.90 \\
4-pedotransfer & $95-130$ & & 1.34 & 0.023 & 0.06 & 0.39 & 17,89 \\
4-adjusted & $120-200$ & & 1.34 & 0.023 & 0.06 & 0.43 & 40,00 \\
\hline
\end{tabular}

Table 2. Water transfer parameters of the Van Genuchten water retention curves, Chromic Luvisol soil profile, Chelopechene. 


\begin{tabular}{|c|c|c|c|c|c|}
\hline \multirow[t]{2}{*}{ Lysimeter } & \multirow[t]{2}{*}{ Depth, cm } & \multicolumn{4}{|c|}{ Periods of maize vegetation season (DOY) } \\
\hline & & $156-171$ & $171-202$ & $202-218$ & $218-268$ \\
\hline \multirow[t]{5}{*}{ EFI- $\gamma_{\mathrm{w}}$} & $0-30$ (wf)* & $1.10^{-5}$ & $5.10^{-6}$ & $5.10^{-6}$ & $5.10^{-7}$ \\
\hline & $0-30(r)$ & 0.001 & 0.005 & 0.005 & 0.0005 \\
\hline & $30-70$ & 0.001 & 0.0001 & 0.0001 & $1.10^{-5}$ \\
\hline & $70-120$ & 0.001 & 0.0001 & 0.0001 & $1.10^{-5}$ \\
\hline & $120-200$ & 0.0001 & $1.10^{-5}$ & $1.10^{-5}$ & $1.10^{-6}$ \\
\hline EFI-c $\mathrm{c}_{\mathrm{NO} 3 \mathrm{~s}}$ & & 0.01 & 0.15 & 1 & 1 \\
\hline \multirow{6}{*}{ AFI- $\gamma_{w}$} & 0-30 (wf) & $1.10^{-5}$ & $5.10^{-7}$ & $5.10^{-7}$ & $5.10^{-7}$ \\
\hline & $0-30(\mathrm{r})$ & 0.001 & 0.0005 & 0.0005 & 0.0005 \\
\hline & $0-30$ (df) & - & $1.10^{-5}$ & $1.10^{-5}$ & $1.10^{-5}$ \\
\hline & $30-70(2)$ & 0.001 & $1.10^{-5}$ & $1.10^{-5}$ & $1.10^{-5}$ \\
\hline & $70-120(3)$ & 0.001 & $1.10^{-5}$ & $1.10^{-5}$ & $1.10^{-5}$ \\
\hline & $120-200(4)$ & 0.0001 & $1.10^{-6}$ & $1.10^{-6}$ & $1.10^{-6}$ \\
\hline AFI-c $c_{\mathrm{NO}}$ & & 0.01 & 0.15 & 1 & 1 \\
\hline
\end{tabular}

${ }^{*} \mathrm{wf}$ - below the wet furrow; r- below the ridge; $\mathrm{df}$ - below the dry furrow

Table 3. Solute transfer parameters $\mu_{\mathrm{w}}\left(\mathrm{mg}_{\mathrm{NO} 3} / \mathrm{cm}^{3} / \mathrm{h}\right)$ and $\mathrm{c}_{\mathrm{NO} 3 \mathrm{~s}}\left(\mathrm{mg}_{\mathrm{NO} 3} / \mathrm{cm}^{3}\right)$ in Eq. (2) after validation relative to EFI (step v) and AFI (step vi), cropped lysimeters, 1997. 
Aldhor-produced version of the final draft post-refeerinff at $\mathbf{4 0} \mathrm{cm}$ depth Original publication available at 10.1016/j.agwat.2007.10.021 (Elsevier)

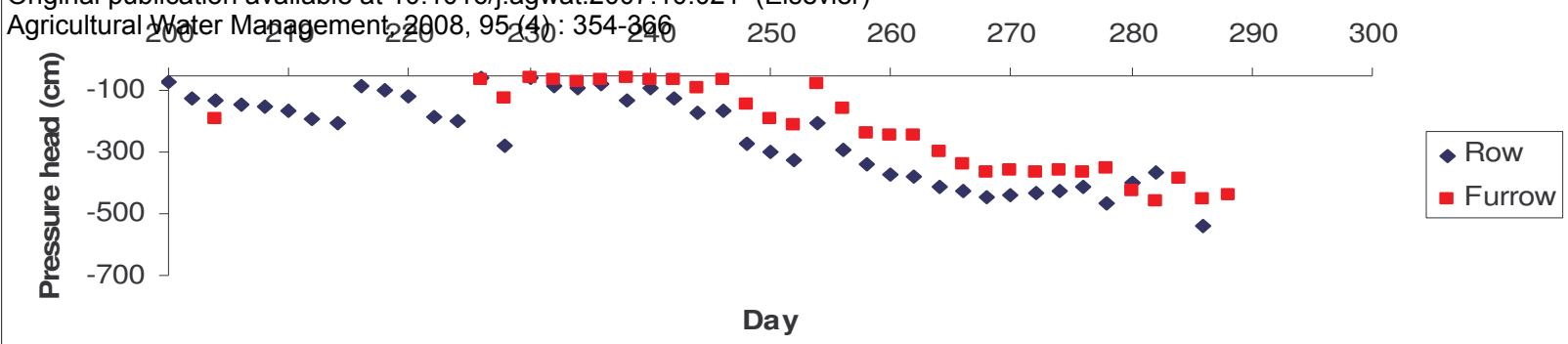

b)

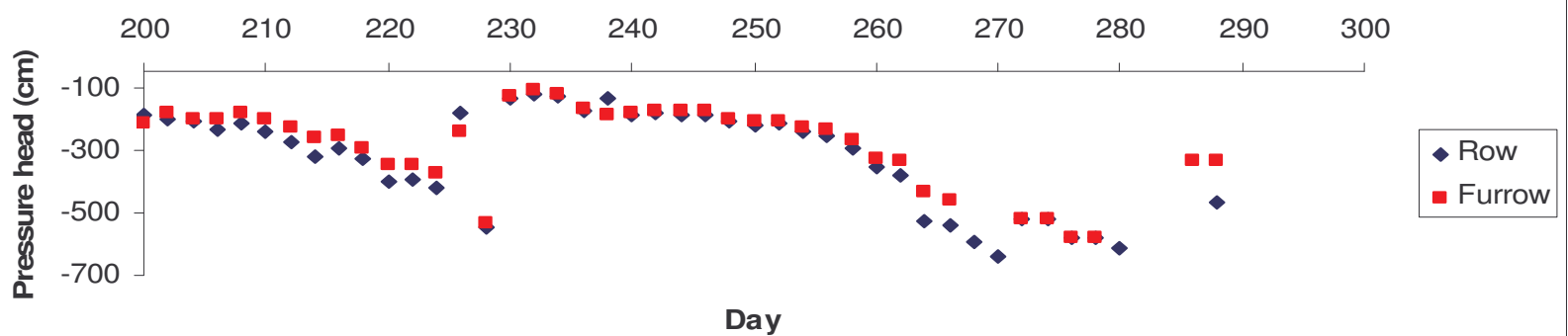

c)

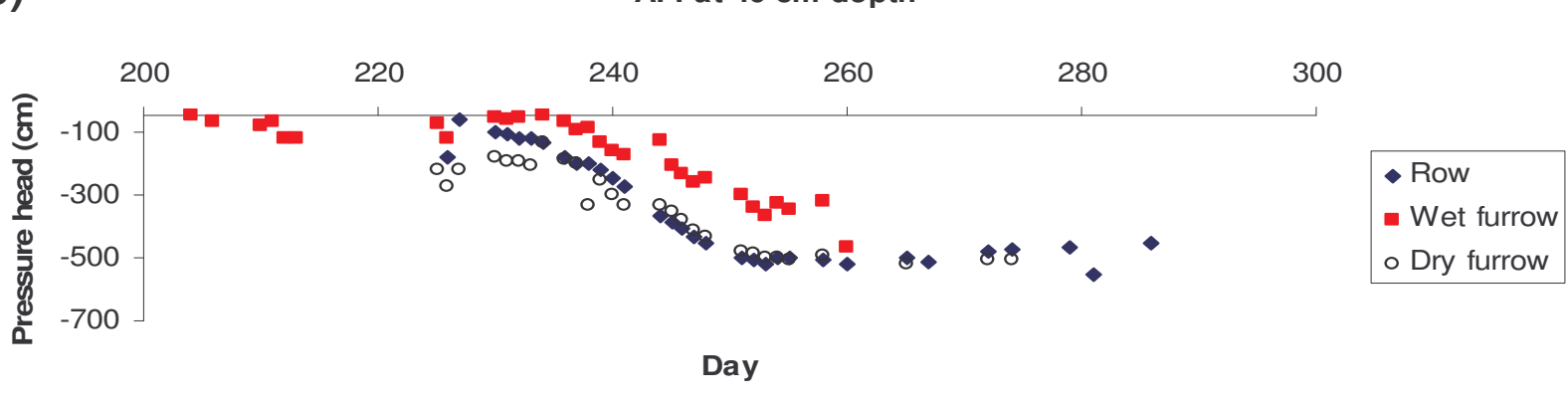

AFI at $40 \mathrm{~cm}$ depth

d)

AFI at $100 \mathrm{~cm}$ depth

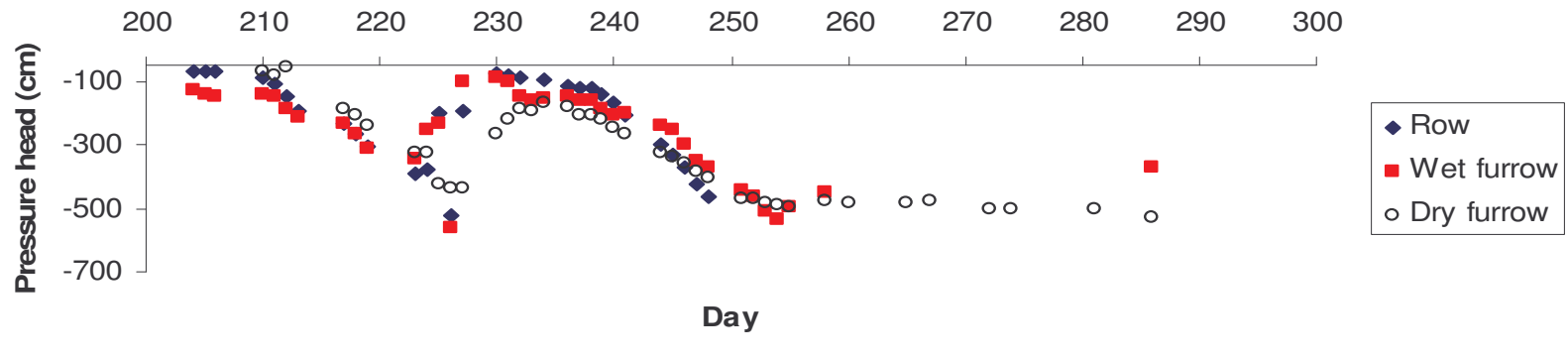

e)

Precipitation / Irrigation

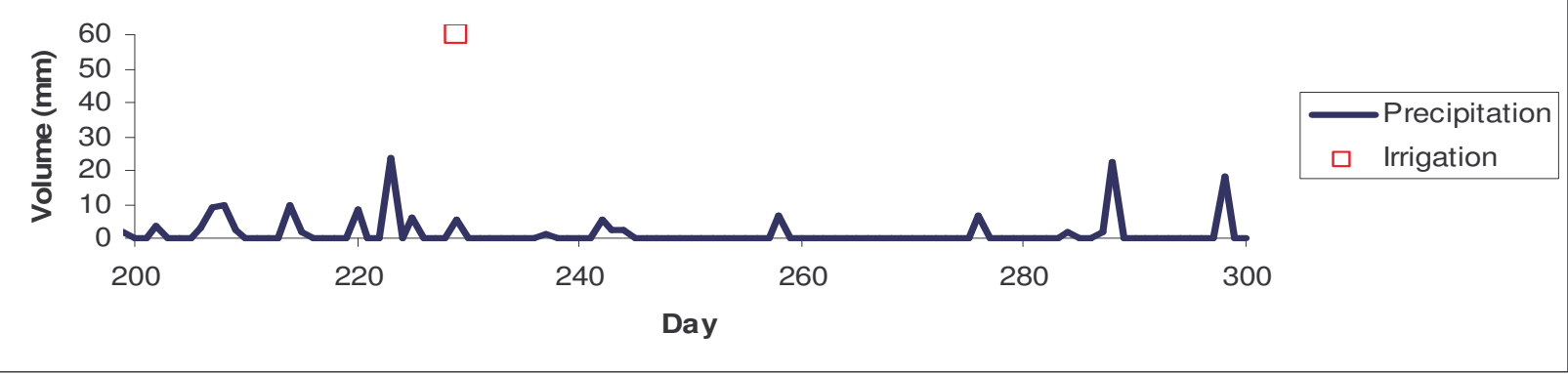

Fig. 1. Pressure head evolution at $40 \mathrm{~cm}$ and $100 \mathrm{~cm}$ under EFI a) and b) and AFI c) and d), precipitation and irrigation (e). 


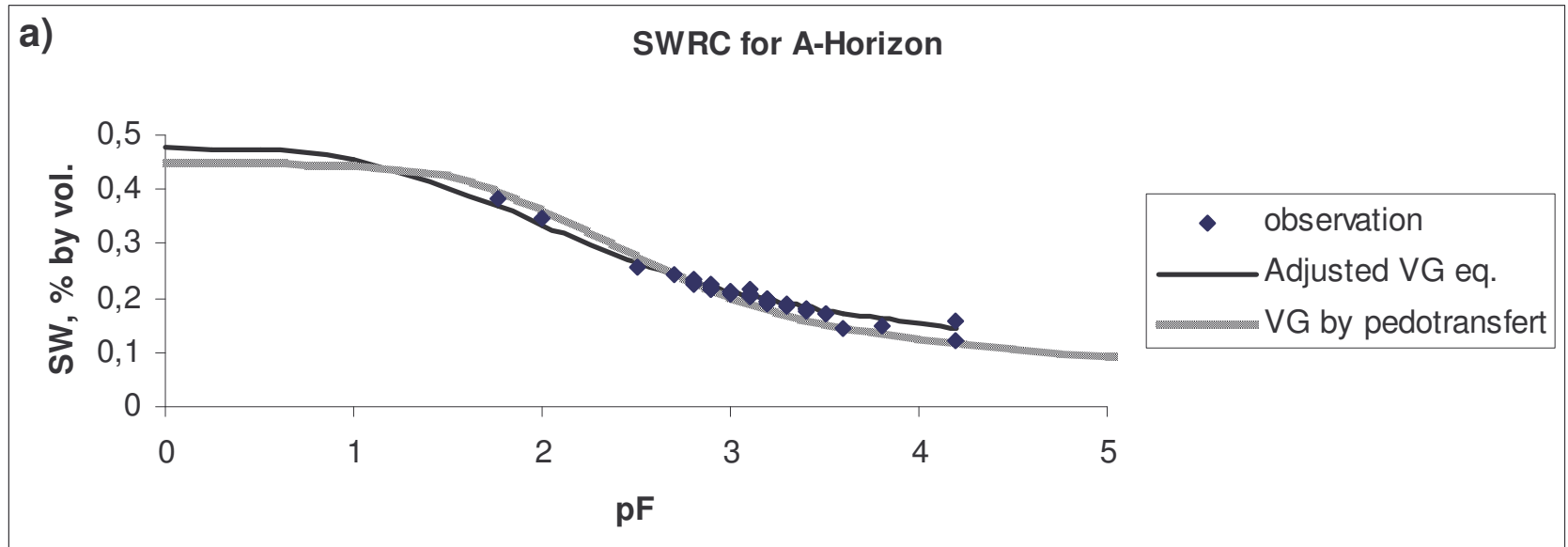

b)

SWRC for B-Horizon

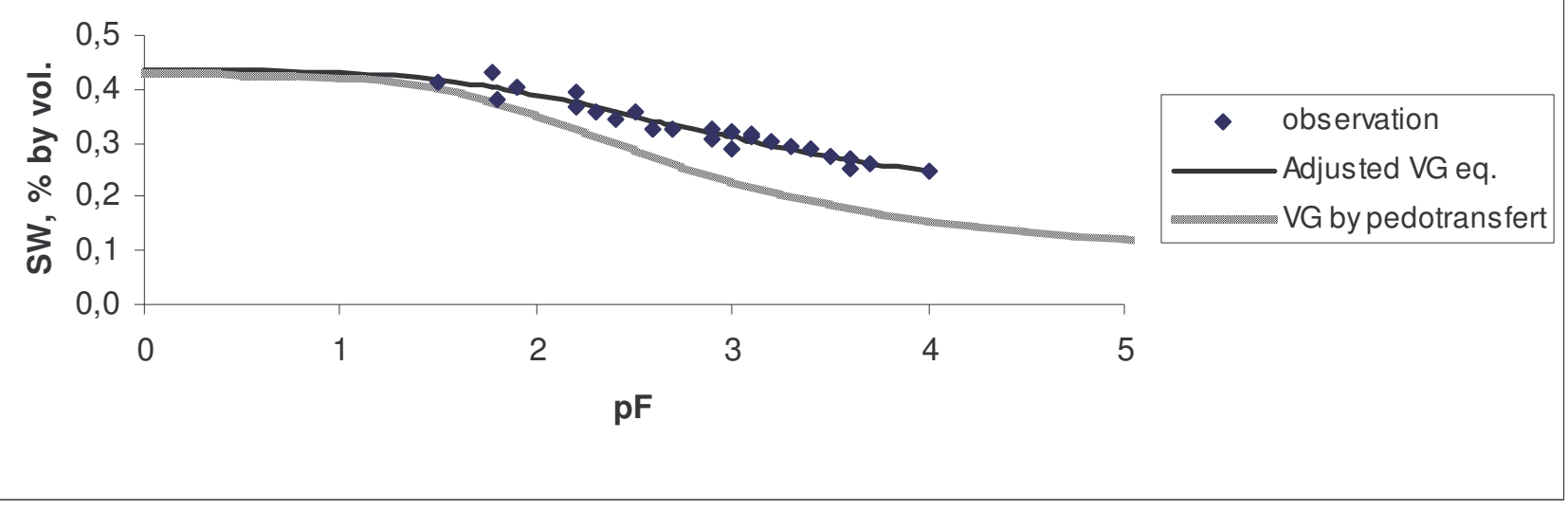

c)

SWRC for C-Horizon

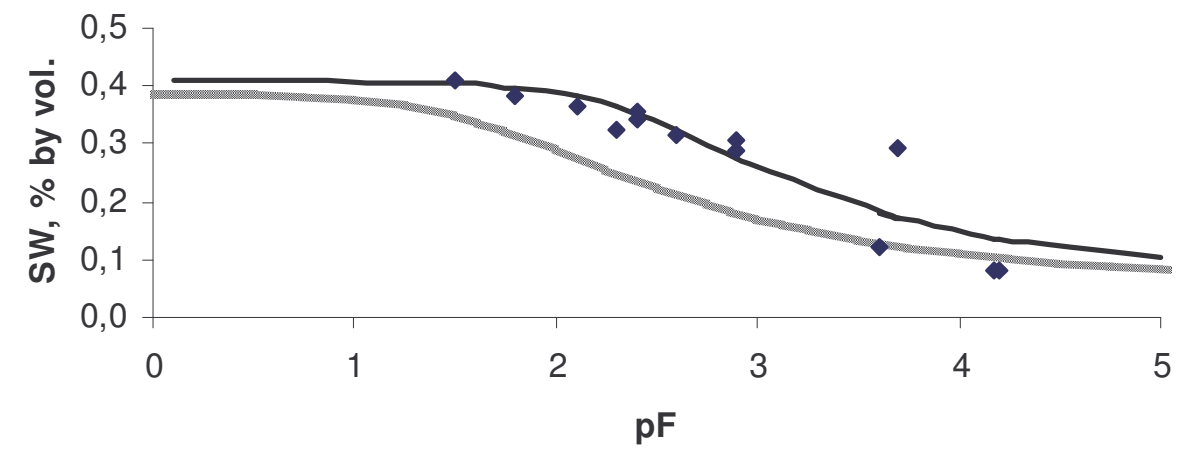

- observation

Adjusted VG eq.

VG by pedotransfert

Fig. 2. Laboratory based (Koleva, 1973) and adjusted VG water retention curve for: AHorizon $(0-30 \mathrm{~cm})$, Bulk density $1.3 \mathrm{~g} / \mathrm{cm}^{3}$ (a), B-Horizon $(30-75 \mathrm{~cm}$ and $75-120 \mathrm{~cm})(\mathrm{b})$ and C-Horizon $(120-200 \mathrm{~cm})(\mathrm{c})$ compared to those predicted by PTFs and field observations. 


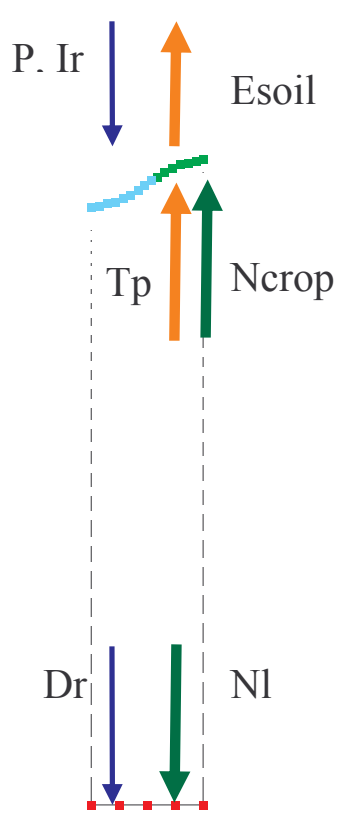

(e)

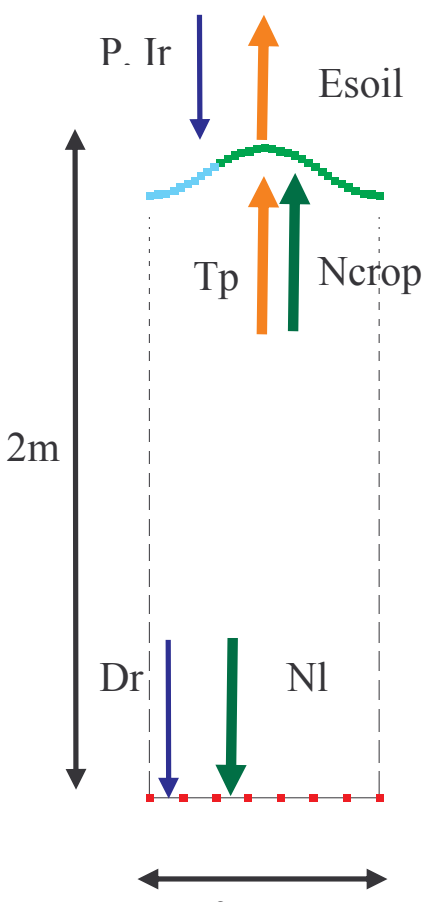

$0.75 \mathrm{~m}$

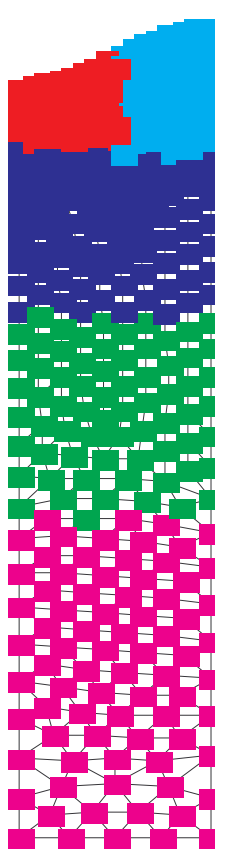

(f)
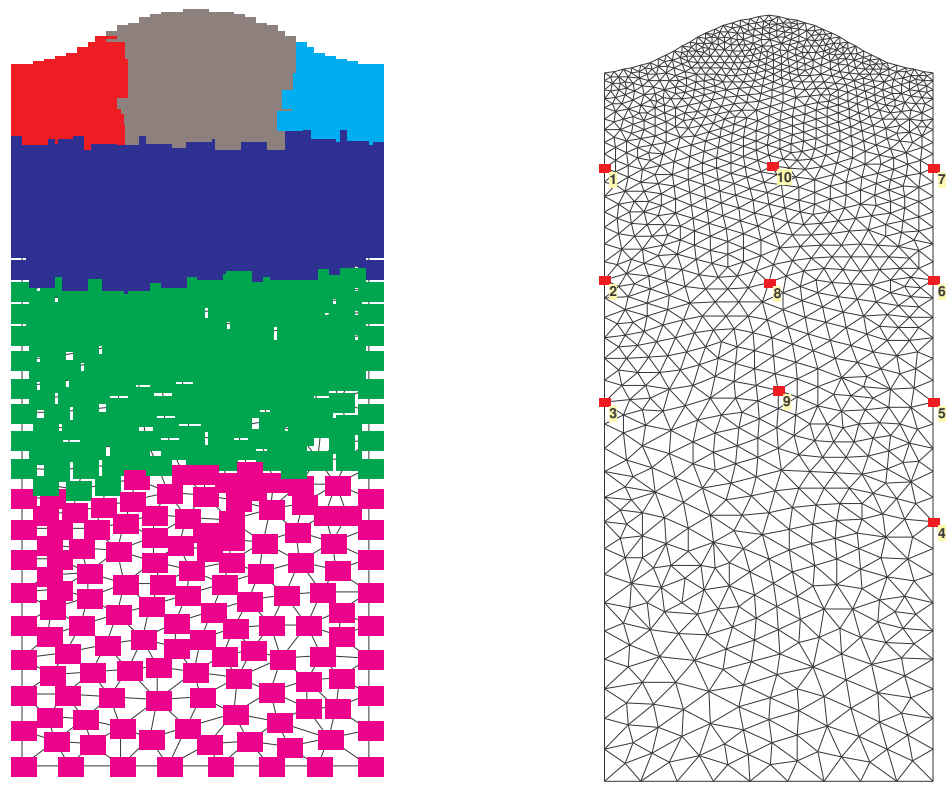

Fig. 3. HYDRUS2D model calibration for EFI/AFI lysimeter: a) and e) boundary conditions for 2D simulation; b) and f) soil layers and $\mu_{\mathrm{w}}$ coefficient calibration regions for step $\mathrm{v}$ and vi; c), d) and g) observation nodes for SW in step ii and for PH in step iii and iv 
Author-produced version of the final draft post-refeering

Original publication available at 10.1016/j.agwat.2007.10.021 (Elsevier)

Agricultural Water Management, 2008, 95 (4) : 354-366
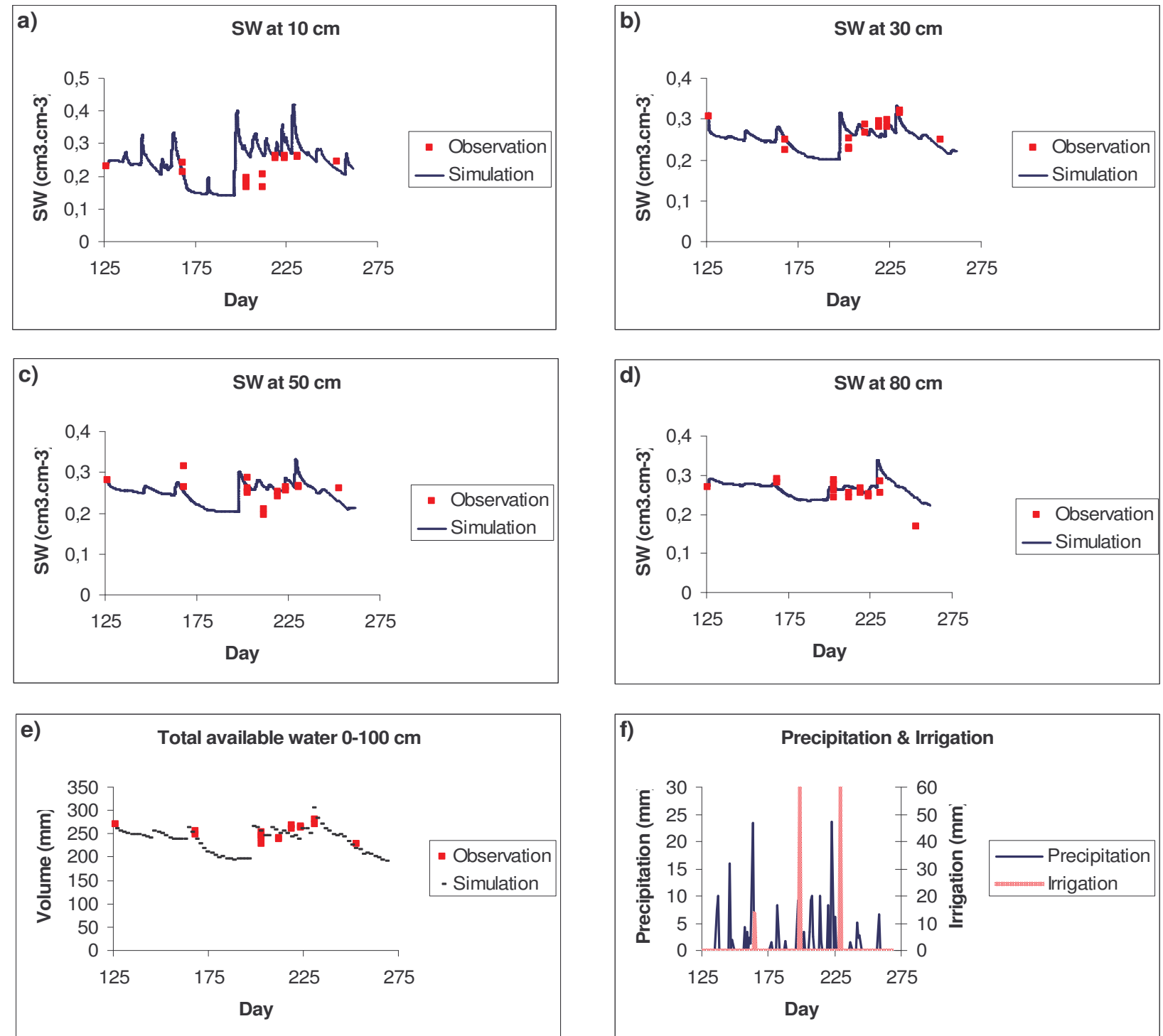

Fig. 4. Comparison between numerical results of step (ii) and observations in EFI lysimeter, 1997. 


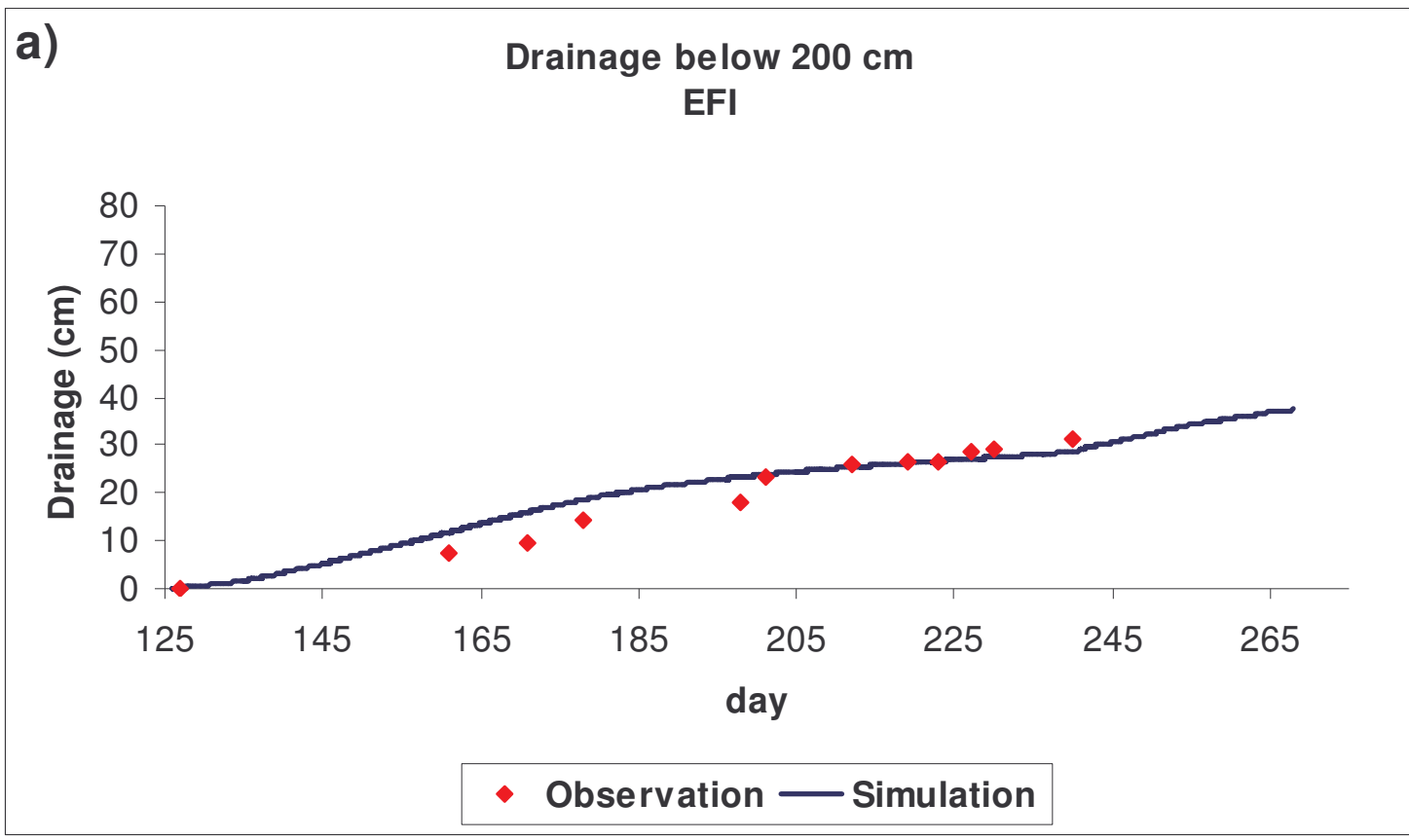

b)

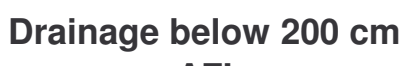

AFI

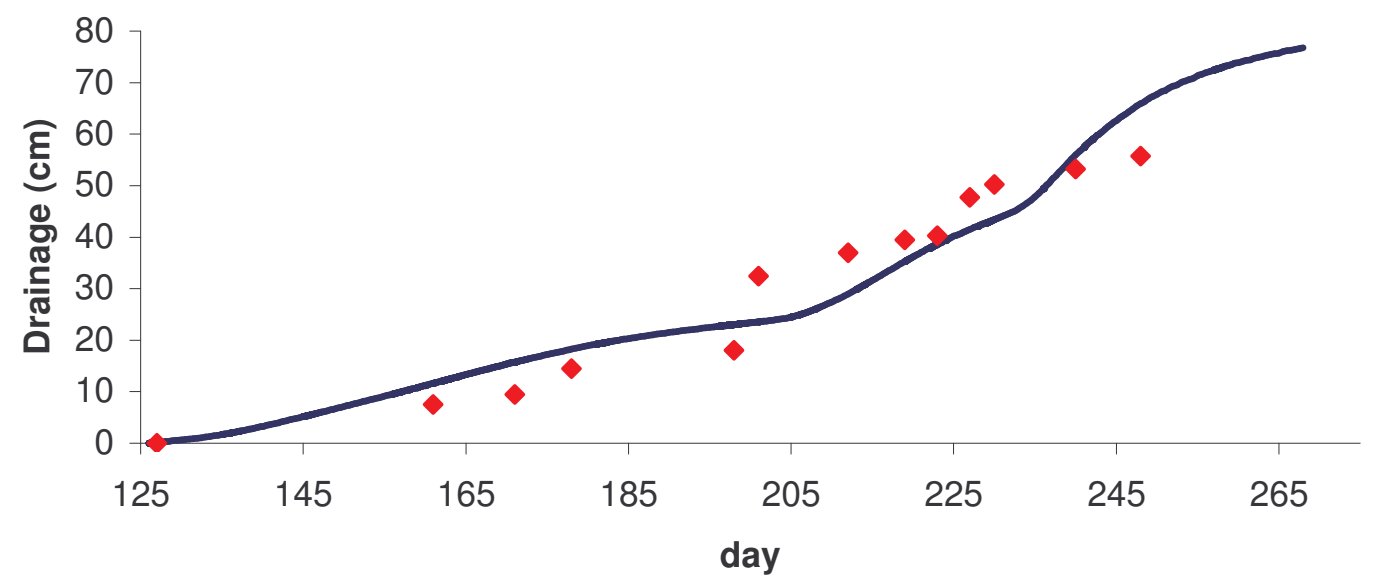

\section{- Observation - Simulation}

Fig. 5. Graphical test of numerical cumulative Drainage results against field observations, 2D water transfer for EFI (step iii) and AFI (step iv). 

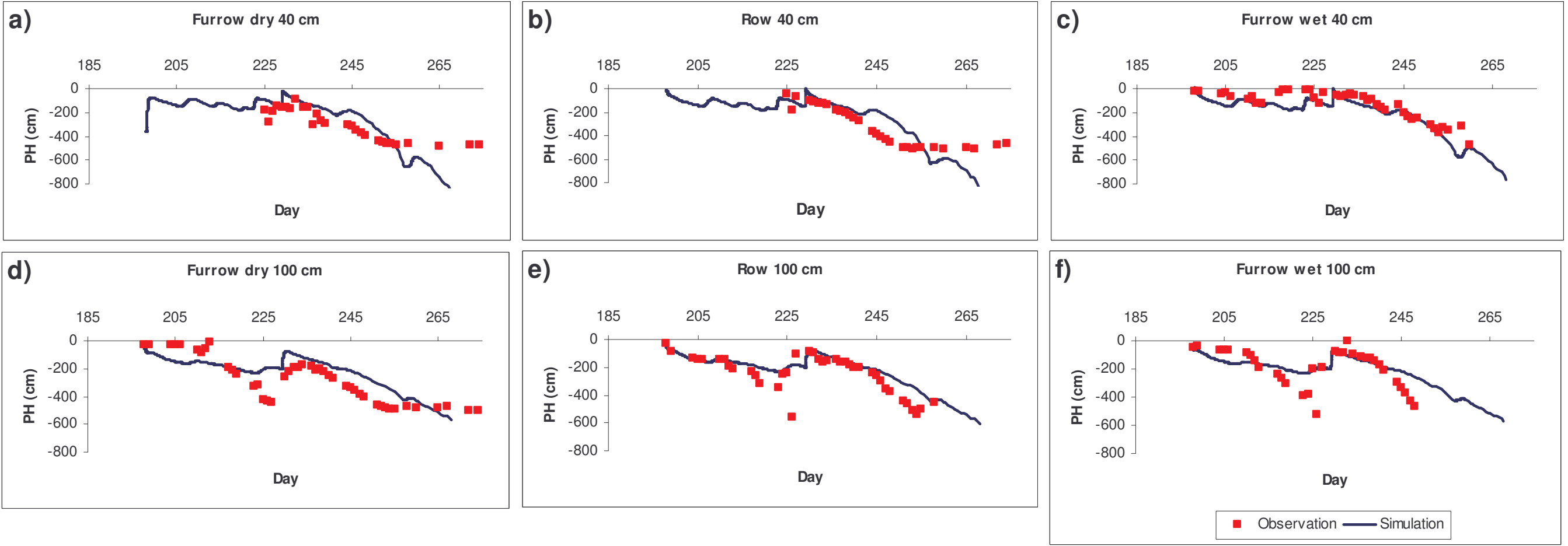

Fig. 6. Validation of step (iv) : comparison of predicted PH with observed in irrigated/non-irrigated furrows and ridge in AFI lysimeter. 
Author-produced version of the final draft post-refeering

Original publication available at 10.1016/j.agwat.2007.10.021 (Elsevier)

Agricultural Water Management, 2008, 95 (4) : 354-366 

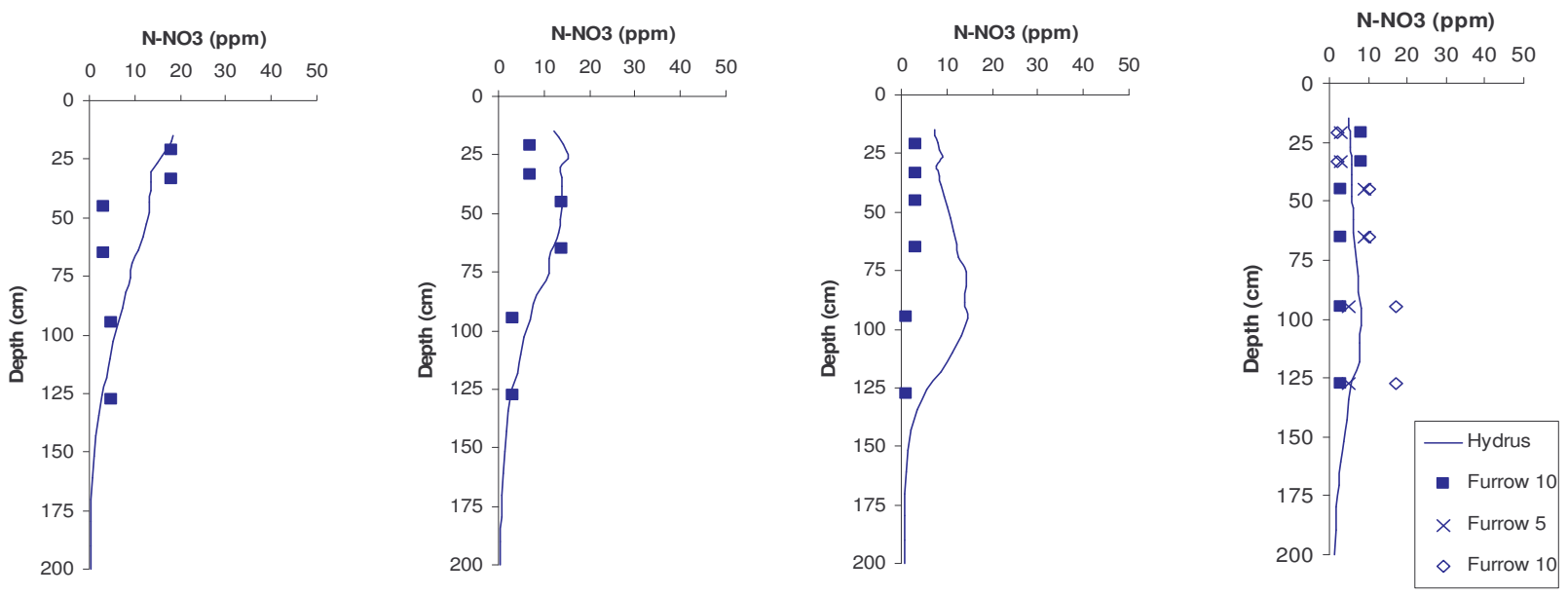

Ridge (DOY171)

Ridge (DOY202)
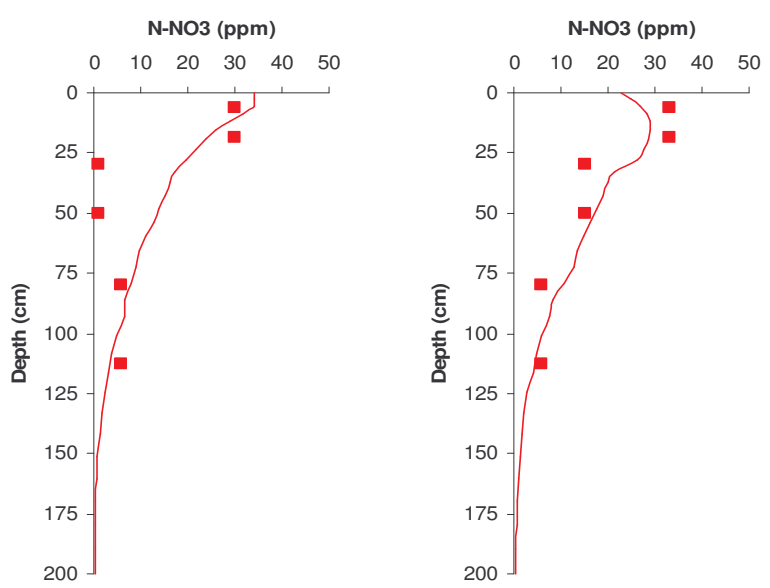

Ridge (DOY226)

Ridge (DOY268)
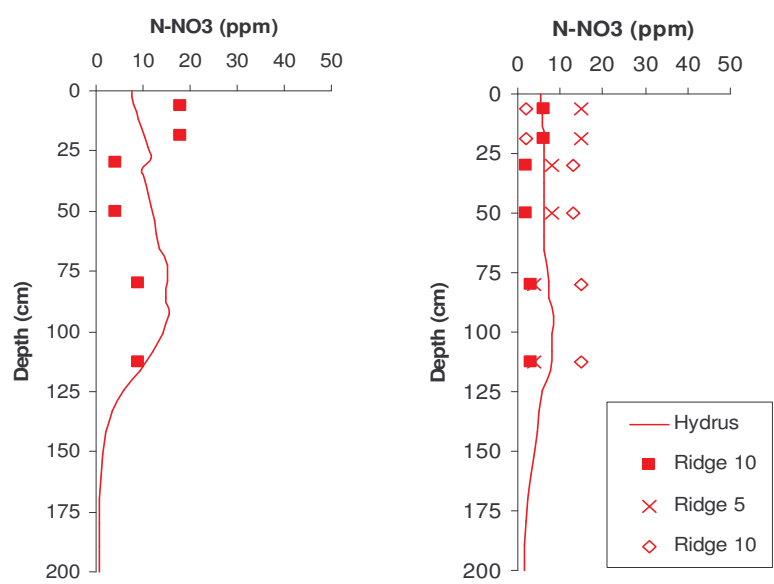

Fig. 7. Simulated and observed soil $\mathrm{N}-\mathrm{NO}_{3}$ profiles below the furrow and the ridge for EFI Lysimeter (step v), 5/06-25/09/1997 
a) wet furrow (DOY268)

\section{N-NO3 (ppm)}

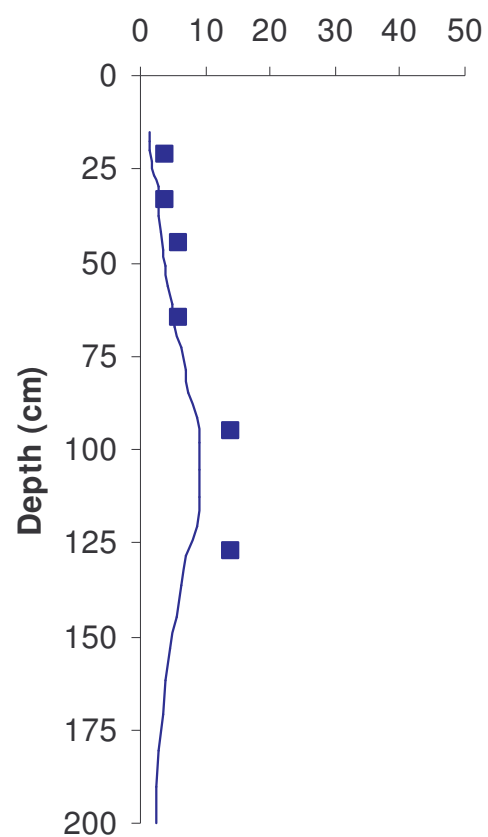

b)

Ridge (DOY268) N-NO3 (ppm)

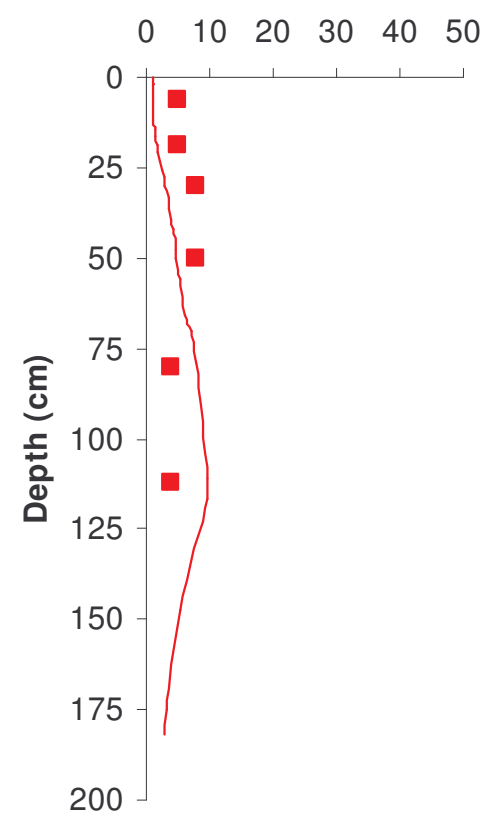

c)

Dry furrow (DOY268)

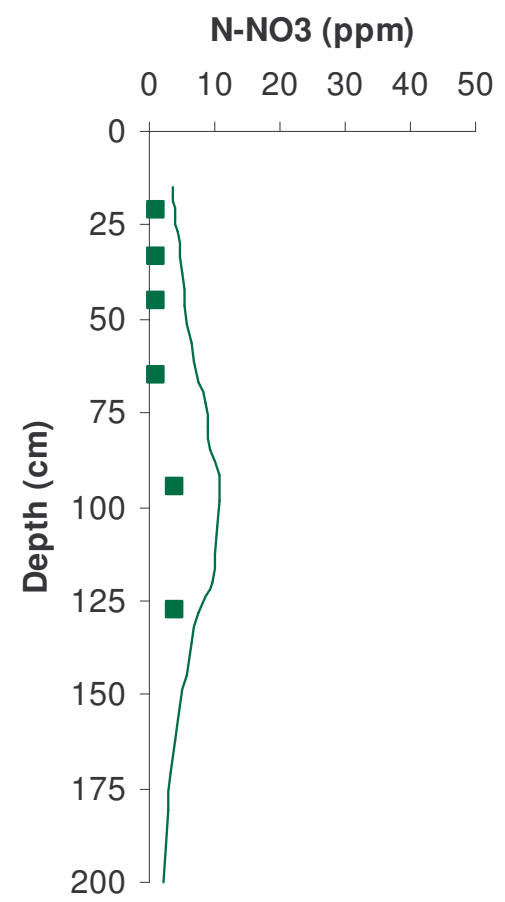

Fig 8. Simulated and observed residual soil nitrate concentrations under the wet furrow (a), ridge (b) and dry furrow (c) relative to AFI lysimeter (step vi), 25/09/1997 (day 268). 
(a)
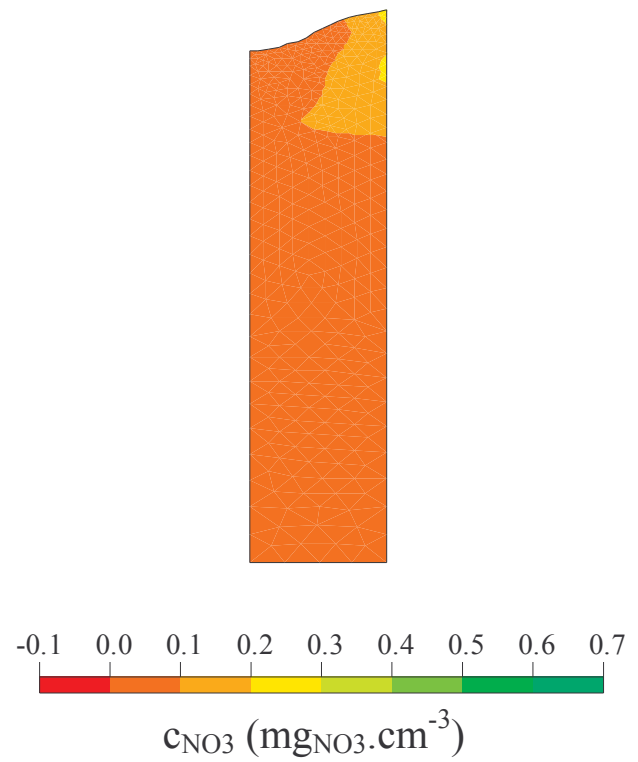

(c)

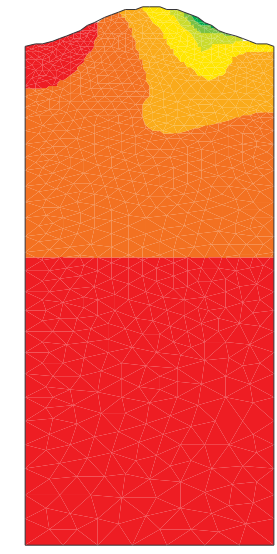

$\begin{array}{llllllllll}0.00 & 0.05 & 0.10 & 0.15 & 0.20 & 0.25 & 0.30 & 0.35 & 0.40 & 0.45\end{array}$

$$
\mathrm{c}_{\mathrm{NO} 3}\left(\mathrm{mg}_{\mathrm{NO} 3} \cdot \mathrm{cm}^{-3}\right)
$$

(b)

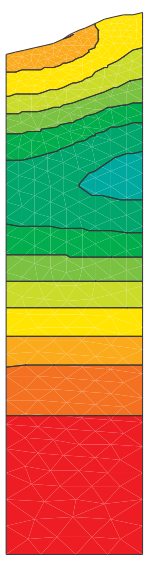

$\begin{array}{llllllllll}0.00 & 0.01 & 0.02 & 0.03 & 0.04 & 0.05 & 0.06 & 0.07 & 0.08 & 0.09\end{array}$

$\mathrm{c}_{\mathrm{NO} 3}\left(\mathrm{mg}_{\mathrm{NO} 3} \cdot \mathrm{cm}^{-3}\right)$

(d)

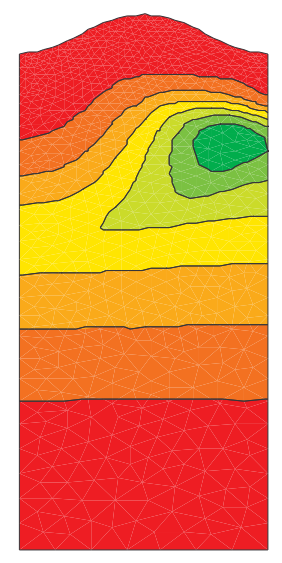

$\begin{array}{llllllllll}0.00 & 0.02 & 0.04 & 0.06 & 0.08 & 0.10 & 0.12 & 0.14 & 0.16 & 0.18\end{array}$

$\mathrm{c}_{\mathrm{NO} 3}\left(\mathrm{mg}_{\mathrm{NO} 3} \cdot \mathrm{cm}^{-3}\right)$

Fig. 9. Advancement of the nitrate profile for EFI and AFI lysimeter at the end of second (day 198) a) and c) and third (day 224) b) and d) irrigation event. 


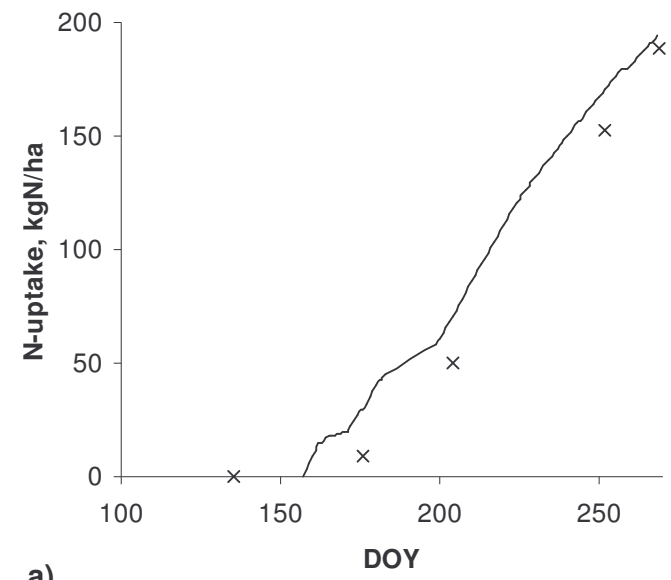

a)

Fig. 10. Simulated and observed N-uptake by the plant for EFI, 1997.

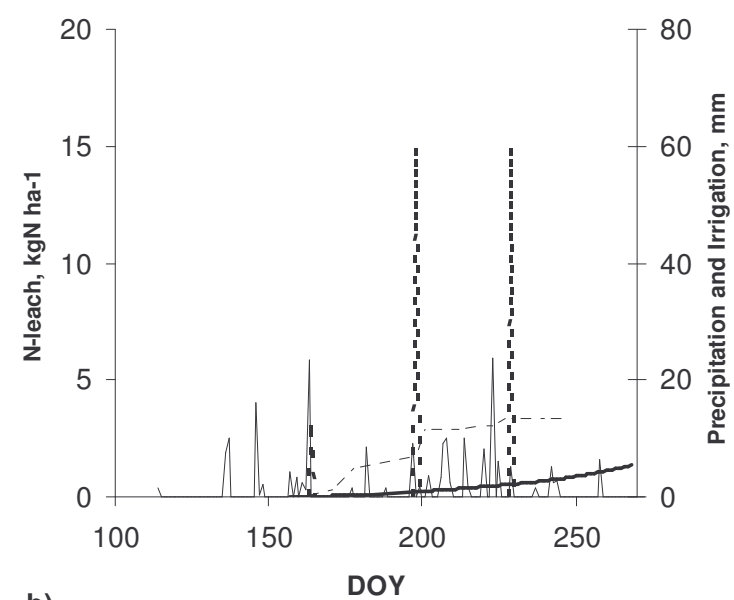

b)

DOY

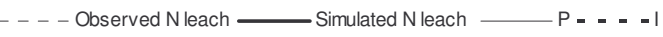

Fig. 11.Simulated and observed N-leaching at the bottom boundary for EFI, 1997. 